\title{
El Libro de Gracián como representación social (Castilla, siglo XV)
}

The Libro de Gracián as a social representation (XVth Century, Castile)

Roque Sampedro López

DOI: https://doi.org/10.24215/23468971e122

Universidad de Santiago de Compostela, España

roquesampedro@gmail.com

Recepción: 07 Abril 2020

Aprobación: 01 Junio 2020

\section{Resumen:}

El presente trabajo analiza cómo el texto El libro de Gracián es una representación crítica de la realidad social-política de la primera mitad del siglo XV castellano, coincidente con el reinado de Juan II. Para ello, la obra de Roger Chartier resulta el basamento teórico para pensar esa representación, que no solo está mostrando una realidad, sino que también incorpora interpretaciones e intereses con fines particulares que sobrepasan a la obra literaria en sí.

Palabras clave: Gracián, Representación, Siglo XV, Discursos.

\section{Abstract:}

The present paper Will analyze the Libro de Gracián not as a literary work but as a critical representation of the society of the first half of the Castilian XVth century. The work of Roger Chartier will be the theoretical foundation of this paper so as to contemplate said representation not only as a mere showing of a reality but as one that contains interpretations and interest with a specific goal in mind.

KEYWORDS: Gracian, Representation, XVth century, Discourse.

\section{INTRODUCCIÓN}

El propósito de estas páginas es analizar algunos elementos de un texto castellano del reinado de Juan II (1405-1454), el Libro de Gracián ${ }^{1}$ a partir del concepto de representación. El «Libro de Gracián» funciona como una representación social de la realidad sociopolítica del mundo castellano de la primera mitad del siglo XV. La obra, a través de la narración del viaje imaginario de Gracián, el muchacho que protagoniza nuestro texto incluye toda una serie de elementos que posibilitan el análisis que pretendemos aquí. Hablamos de reflexiones de carácter sociopolítico puestas en la boca de diferentes personajes, de la caracterización y definición de diferentes "órdenes sociales", de la construcción de una sociedad ideal ligada a un pasado imaginado, de la apropiación de la obra de Ramón Llull, o del fuerte discurso crítico que se aprecia en la denuncia de los privados como una de las causas del mal gobierno del reino. En definitiva, como veremos, el «Libro de Gracián» se aproxima de manera crítica a la sociedad de su momento, generando un discurso que analizaremos aquí de manera tentativa.

En un sentido teórico, recurriremos, fundamentalmente, a la obra de R. Chartier a la hora de definir la noción de representación. Esta herramienta teórica, extraída de lo que se ha venido llamando nueva historia cultural, supone pensar los textos como discursos que incluyen no sólo referencias a una realidad, sino que incorporan las interpretaciones, aspiraciones, intereses y pensamientos de los agentes que los generan. El «Libro de Gracián», en esta línea, no es un reflejo realista del reinado de Juan II, sino que despliega una serie de estrategias discursivas para, de alguna manera, intervenir en la vida social y política de la Castilla del momento.

Con todo, cabe insistir en el carácter tentativo de este artículo, cuyo objetivo se orienta, como ya se ha mencionado, a explorar algunas de las posibilidades de la aplicación de la noción de representación a este 
relato. Para ello, en primer lugar, se expondrán las problemáticas del «Libro de Gracián» en relación con su contenido, estructura, autoría, y el contexto en el que se ubica. En segundo lugar, profundizaremos en la noción de representación, explicando algunos de sus rasgos y señalando cómo pueden funcionar a la hora de aplicarlos al texto. Finalmente, analizaremos con más concreción la dinámica de las representaciones del relato, a través de la crítica que se realiza a privados y conversos, a los que se identifica como corruptores del orden social.

\section{TeXTO, AUTORÍA Y CONTEXTO}

A la hora de estudiar la representación y articulación de diferentes grupos sociales en un texto medieval -en este caso, el «Libro de Gracián»-, partimos de una posición teórica e historiográfica, derivada de las llamadas nueva historia cultural y nueva historia intelectual. ${ }^{2}$ En este sentido, este artículo girará en torno a la idea de que el «Libro de Gracián» es una representación -o un sistema de representaciones-. Como veremos, se entenderá el concepto de "representación" no sólo como una expresión de la realidad social, que pueda ser verdadera o falsa, fidedigna o dudosa; sino más bien, sin desmerecer estos aspectos, como una forma de construir la realidad social. Esto es, partiremos de la idea de que las representaciones que presenta el «Libro de Gracián» tienen un carácter performativo. Para ello, en este apartado, explicaremos brevemente en que consiste el «Libro de Gracián», esto es, su contenido, estructura y autoría, para después profundizar en esta idea de representación, especialmente a través de la obra de R. Chartier.

El «Libro de Gracián», un texto anónimo escrito entre 1425 y 1450, consiste en la narración del viaje de un muchacho, Gracián, quién, tras recibir una serie de enseñanzas de su padre acerca de la Creación, los prelados y los príncipes, recorre el "reino" (Castilla), viendo toda clase de abusos, especialmente a manos de nobles, caballeros y privados. El viaje del muchacho termina cuando, tras haber salido del reino y presenciado la corte de una suerte de "rey ideal", vuelve a casa, descubre que su padre ha muerto y se retira a un monasterio.

Así, el texto contiene una buena carga de reflexión sobre la política y la sociedad de la época. En primer lugar, a través de las enseñanzas que Gracián recibe de su padre, un burgués, que ya introduce una crítica de carácter más bien abstracto en torno a las figuras de prelados, príncipes y especialmente privados y consejeros. Además, los abusos que Gracián presencia durante el viaje van acompañados por conversaciones con diferentes personajes, que también incluyen reflexiones sobre el poder de los reyes, el tiranicidio o el Anticristo. Y, por supuesto, estas conversaciones plasman una visión determinada sobre diferentes colectivos (mercaderes, judíos, letrados, jueces, etc.). En este sentido se articula una determinada representación del mundo social, que incluye reflexiones más o menos abstractas (las enseñanzas) y la construcción de un imaginario a través del viaje (vale la aclaración que la estructura del texto ha sido analizada por F. Gómez Redondo, 2002)

Con todo, el «Libro de Gracián» funciona especialmente en relación con su principal influencia, el filósofo mallorquín R. Llull. El «Libro de Gracián» es, en muchos sentidos, una construcción luliana. Así, podemos hablar de una "apropiación" de la obra de R. Llull, que forma una parte fundamental de la articulación del «Libro de Gracián» como representación o sistema de representaciones. Veremos más adelante la relación entre "apropiación" y "representación". Por lo de pronto, el relato del «Libro de Gracián» incorpora la obra del filósofo mallorquín de diversas maneras. En primer lugar, a través del uso directo de determinados fragmentos de la obra de R. Llull, que se integran en la narración de distintas maneras. La traducción de pasajes de textos lulianos como el Llibre de meravelles, el Llibre d'intenció, la Doctrina pueril, el Blanquerna, o el Llibre de mill proverbis, forma parte de la elaboración del «Libro de Gracián», ya sea en partes de carácter más "doctrinal” -como pueden ser los capítulos tercero y cuarto, dedicados a prelados y príncipes- o en el propio viaje que Gracián realiza por Castilla. En segundo lugar, el propio marco narrativo de la obra parece inspirado en el «Llibre de meravelles». En ambos relatos, un muchacho -Félix en el texto luliano, Gracián en el castellano- sale a recorrer el mundo aleccionado por su 
padre, aunque los viajes de ambos son bastante diferentes -el de Félix tiene un carácter enciclopédico, el de Gracián, sociopolítico-.

En lo tocante a la autoría, como se ha indicado el texto es anónimo. Ahora bien, es posible situar un promotor, el arzobispo de Sevilla, Diego de Anaya y Maldonado (1357-1437) (Monsalvo Antón, J. M., 2014). El único manuscrito en el que se conserva el «Libro de Gracián» fue propiedad del arzobispo, incluso un objeto cultural promovido por él. ${ }^{3}$ Además, varios elementos del texto parecen reflejar los intereses de don Diego, pues reflejaría su enfrentamiento con el Condestable de Castilla, Álvaro de Luna, privado de Juan II. El favorito del rey habría conseguido, acusando a Diego de Anaya de ser partidario del antipapa Benedicto XIII, que retiraran a este de la sede de Sevilla. En este sentido, la fuerte crítica que en el texto se realiza contra los privados, a quienes se considera prácticamente principales responsables de la decadencia moral del reino, puede entenderse como una crítica a la figura de Álvaro de Luna, personaje, además, muy controvertido en su momento. Así, el texto refleja los intereses Diego de Anaya, su enfrentamiento con el Condestable, por lo que cabe ampliar la noción de autoría ${ }^{4}$ para abarcar también al promotor del texto. Se trataría de pensar el concepto de autoría de una forma más elaborada, incluyendo no sólo al autor material de la obra, sino también todo elemento que influya en la composición del texto.

Finalmente, podemos hablar de un contexto sociopolítico en el que se sitúa el «Libro de Gracián», fundamentalmente el reinado de Juan II. Se trataría de un momento complicado en la vida política castellana, un momento plagado por los conflictos entre Álvaro de Luna y los infantes de Aragón en torno a la influencia sobre la monarquía castellana. Asimismo, también se podría hablar de un momento de transformación de la noción de monarquía, de manera que se debate el propio concepto de rey (Nieto Soria, J. M., 1998). Nuestro texto, en cierto sentido, podría entenderse como una participación en los debates de la vida política castellana, jugando la noción de rey un papel importante en la obra -el capítulo IV se dedica a los príncipes-. Tendríamos que incluir aquí, además, la posible relación entre la crítica a los privados, y la crítica a Álvaro de Luna

En definitiva, el «Libro de Gracián» se nos presenta como un relato de viajes con una fuerte crítica sociopolítica. El relato se construye, en buena medida, a partir de la obra de R. Llull. A mayores, el texto está relacionado con los conflictos entre Diego de Anaya y Álvaro de Luna, reflejando las posiciones políticas e intereses del primero, y, de una manera general, participa en un contexto de conflictividad política y social.

\section{El Libro de Gracián como representación}

Una vez realizada esta primera aproximación al «Libro de Gracián» conviene clarificar el principal elemento teórico con el que se pretende abordar el texto. Nos referimos al concepto de "representación". Así, partimos de la elaboración de R. Chartier (1992; 2005 y 2007), que nos permitirá entender el «Libro de Gracián» como un conjunto de representaciones, es decir, como un discurso. El «Libro de Gracián» es, en este sentido, una forma de significar la realidad, un relato que produce una determinada interpretación de la Castilla del siglo XV, a través de toda una serie de elementos: el "adoctrinamiento estatal”, el viaje, los exempla, etc. Ahora bien, las representaciones, en el sentido que le damos aquí, no son un simple reflejo de la realidad, sino que tienen una serie de características que resultan de interés a la hora de entender el «Libro de Gracián»:

a) Las representaciones construyen una realidad. Las representaciones no son una simple constatación de la realidad, más o menos acertadas, sino que también tienen efectos sobre ella. Así, toda representación incluye una serie de referentes reales, pero también organizan las relaciones entre dichos referentes, dan un sentido a los acontecimientos, generan expectativas o defienden normas. El «Libro de Gracián» se refiere a una realidad en la que existen príncipes, privados, ciudades (como Córdoba o Lepe) o abusos nobiliarios (Ladero Quesada, M. A., 2016), pero también interpreta esos referentes de una manera determinada, afirmando que los problemas de su sociedad vienen dados por la corrupción de los príncipes y esta, a su vez, por la presencia de privados y consejeros. Además, el carácter performativo de las representaciones también se refiere a los efectos que estas puedan tener en la realidad social, cuando los individuos y grupos se piensan a sí mismos y a 
los demás de acuerdo con las interpretaciones y normas de dichas representaciones, y actúan en consecuencia. Por ejemplo, se ha argumentado que el «Libro de Gracián» forma parte de toda una serie de discursos que "construyen" a Álvaro de Luna como un tirano, una idea que influiría en su ajusticiamiento en 1453 (Nieto Soria, J. M., 2017). ${ }^{5}$

b) Las representaciones también tienen un componente colectivo. Expresan las ideas, los intereses o las prácticas de un determinado grupo social (Chartier, R., 1992, pp. 27-28), que no es fácilmente definible en términos socioeconómicos, profesionales, sexuales, o geográficos. No hay un elemento previo al discurso que permita delimitar los intereses que transmiten las representaciones. Más bien, el propio grupo social se genera en la interacción entre elementos reales (estructura social, recursos materiales, etc.), y elementos discursivos. ${ }^{6}$ Es difícil determinar a qué grupo social pertenece el "no-autor" del texto, y qué intereses se transmiten en la representación. Aun así, es posible apuntar algunos elementos. Por una parte, el «Libro de Gracián» procede de los círculos intelectuales de Diego de Anaya, y en este sentido parece articular el pensamiento del arzobispo de Sevilla. Por otra, en el texto circulan ideas, críticas, y referencias que también están presentes en el «Cancionero de Baena». ${ }^{7}$ Esto incluiría diversas críticas de carácter sociopolítico y referencias a R. Llull. ${ }^{8}$ A mayores, habría que plantear la posibilidad de que el autor formase parte de la Orden de San Jerónimo, ya que, según J. J. Satorre, el «Libro de Gracián» contiene rasgos que encajan con la espiritualidad de esta orden (Satorre, J. J., 1980, pp.189-191). ${ }^{9}$ Así, tenemos un autor atravesado por, al menos, tres identidades: su relación con Diego de Anaya, su relación con el entorno del «Cancionero de Baena», y su relación con (o pertenencia a) los jerónimos.

c) En las representaciones se emplean los recursos culturales (símbolos, textos, saberes), que circulan en una sociedad determinada. Ahora bien, este uso no es homogéneo, esto es, en una representación se puede usar una determinada idea, símbolo o esquema narrativo cambiando su significado. Se trata de una apropiación. Así, el «Libro de Gracián» se apropia de determinados textos de R. Llull, resignificándolos en un contexto narrativo y sociopolítico distinto, lo que lleva a que, con un mismo fragmento, se enfaticen cuestiones distintas. ${ }^{10}$

d) Las representaciones, según R. Chartier, también pueden incluir todo el trabajo de clasificación del mundo social que se da en una sociedad determinado o que emplea un grupo social. Las representaciones, los textos en este caso, incorporan las divisiones sociales y las sitúan dentro de una interpretación o visión del mundo determinada, una visión compartida por el grupo social complejo del que forman parte. En el «Libro de Gracián», buena parte de este trabajo de desglose se da durante la narración del viaje de Gracián, a través de los diversos personajes con los que se encuentra el muchacho, o bien de los que oye hablar. Estos incluyen menestrales, mercaderes, abogados, jueces, recaudadores, u oficiales varios. Por supuesto, la primera parte de la obra, en el que el padre de Gracián adoctrina a su hijo, también incluye reflexiones de este estilo, en torno a prelados, príncipes o privados. En este sentido, se podría decir que, al menos en parte, en el «Libro de Gracián» se recurre a la tradición discursiva medieval que divide el mundo social de manera funcional, ${ }^{11}$ esto es, asignando una función a cada grupo social. Así, por ejemplo, al hablar con un mercader, Gracián afirma que los:

“mercaderes eran estableçidos en los logares, villas $\mathrm{t}$ çibdades por entençión que traigan las cosas nesçesarias a los pueblos et que a estos ayan primera entençión. $t$, por sus trabajos, justiçia consiente que ellos puedan ganar en el ofiçio, mas que el demonio tentava a los mercadores con avariçia, contra esperança t continuación, por tal que ayan supervia contra humildad" (Satorre, J. J., 1981-1983, p.140)

Esta visión funcional y ética no es sorprendente dadas las fuentes de Gracián. En este sentido, como veremos, parte de la obra de R. Llull incluye también la reflexión sobre los órdenes y grupos sociales (Serverat, V., 1991, p.419-423), incluyendo el «Llibre d'intenció» de dónde el autor de Gracián extrae este pasaje sobre los mercaderes. Así, el «Libro de Gracián» en cuanto representación, también funciona como una forma de establecer categorías, clasificaciones, interpretaciones y juicios morales sobre los diferentes elementos que conforman el mundo social. 
e) Finalmente, las representaciones también se pueden caracterizar por su carácter polémico, conflictivo, introduciéndose en un debate en torno a una determinada materia. En este sentido, se podría situar el «Libro de Gracián » dentro de los conflictos en torno a la definición de monarquía que tienen lugar en el siglo XV. Se trata de un momento en el que, a partir de diferentes textos y diferentes colectivos, se contraponen distintas visiones del mundo (con rasgos en común, por supuesto) en torno a lo que debe ser la monarquía, su rol dentro de la sociedad o sus límites. ${ }^{12}$ En este sentido, el «Libro de Gracián» también resulta ser la representación de un pensamiento, de una visión del mundo que, como veremos, señala distintos grupos (privados y conversos, fundamentalmente) como elementos corruptores del orden social.

De alguna manera, estas cuestiones pueden tenerse en cuenta a la hora de estudiar el «Libro de Gracián». Las representaciones no son simplemente reflejos más o menos exactos de la realidad social, sino que tienen una relación compleja con dicha realidad. Son la expresión de una determinada visión del mundo que las preexiste, y al mismo tiempo contribuyen a reproducir o incluso a modificar este pensamiento. Además, su articulación responde a contextos complejos, en este caso, al menos en parte, a las polémicas intelectuales en torno a la decadencia social y a la articulación política de la monarquía. Asimismo, no parece que se trate de representaciones que surgen de un grupo perfectamente delimitado, sino que el «Libro de Gracián» puede ubicarse en relación con el pensamiento de distintos colectivos, conectados entre ellos (poetas del «Cancionero de Baena», el círculo de Diego de Anaya, o la orden de los Jerónimos).

\section{LA REPRESENTACIÓN DE GRUPOS SOCIALES EN EL LIBRO DE GRACIÁN}

Partiendo de la noción de "representación", tal y como ha sido presentada, se analizarán ahora algunos de los elementos del «Libro de Gracián», en relación con las estrategias que se emplean en el texto a la hora de poner en juego el sistema de representaciones que se ha esbozado de manera tentativa. En este sentido, se trata de entender cuáles son las dinámicas del discurso del «Libro de Gracián». Así, veremos cómo el autor anónimo se apropia de los textos lulianos al servicio de unos intereses, buscando siempre la crítica a los privados. Estos se entienden como un elemento disruptivo dentro del orden social. Lo mismo ocurre, como veremos con los conversos. Asimismo, esta representación de privados y conversos se hace posible debido a la construcción de una sociedad ideal, que se proyecta hacia un pasado idealizado.

Para empezar, cabe destacar que, desde un primer momento, la figura del rey aparece como garante del orden social. Partiendo de una atribución habitual en los espejos de príncipes (Nogales Rincón, D., 2006), en el capítulo IV del relato, en el que el burgués explica a su hijo, Gracián, la constitución sociopolítica de la realidad, se afirma que el príncipe debe tener como "primera intención" la justicia en el pueblo, mientras que como "segunda intención" las honras y riquezas. ${ }^{13}$ Se trata del uso de un texto luliano, que refleja la reflexión ética de R. Llull (Cfr. S. Trías Mercant, 1969). Es que uno de los elementos de este pensamiento moral luliano es la fundamentación ética del comportamiento de los diferentes grupos sociales (prelados, príncipes, mercaderes, etc.) (Serverat, V., 1991). Así, para el filósofo mallorquín, las acciones de una persona deben estar ordenadas con una "primera intención" puesta en los fines que son propios de su posición social (la justicia en el caso del príncipe), y una "segunda intención”, puesta en el bienestar personal de la persona en cuestión. La persona y, por lo tanto, el orden social se corrompe precisamente cuando esta sitúa como "primera intención" su satisfacción personal, dejando de lado el fin que es propio de su actividad. Así, por ejemplo, se explica la corrupción de los príncipes en el «Libro de Gracián»: "Fijo, el prínçipe que ha la primera entençión a ser enperador o rey, duque o marqués t ha la segunda a virtudes, estonçes, fijo, desviado es de verdadera entençión” (Satorre, J. J., 1981-1983, p.104). El autor del «Libro de Gracián», en este sentido, se apropia de los textos lulianos que circulan en la Castilla de su momento, a la hora de explicar las funciones y degradación moral de los príncipes.

Ahora bien, esta apropiación no es completa, ya que, en el «Libro de Gracián» la desviación moral de los príncipes respecto a la justicia no viene dada por sí misma, sino que depende fundamentalmente de 
la actuación de otro grupo social. Estos serían los privados y los consejeros. En este sentido, el «Libro de Gracián» se aparta de la imagen que proporciona el «Llibre d'intenció» de R. Llull, que no busca un origen específico de la corrupción de los príncipes, sino que atribuye dicha desviación al demonio, a los vicios, o al alejamiento de Dios, en términos generales. Sin embargo, en el relato castellano, se enfatiza que la corrupción deriva de la avaricia de privados y consejeros, que corrompen al príncipe. Tras evocar un origen ideal, en el que los gobernantes son puestos en su función por el pueblo, ${ }^{14}$ los vicios provienen de la acción de los privados:

"Cresçieron después, fijo, en los prínçipes, errores $\mathrm{t}$ pecados. Et acaesçió en el pueblo novedad de prínçipes $\mathrm{t}$ falsos privados $t$ consejeros. $t$ corronpida fue en los prínçipes justiçia, prudençia, abstenençia, tenprança $t$ caridad $t$ otras vertudes $t$ la ordenaçión sobredicha. Por lo qual, las sus rentas propias que les eran asignadas por voluntad del pueblo diéronlas a los sus malos privados, falsos $t$ lisonjeros, por arterías t engannos que con lo prinçipes t reyes traxeron” (Satorre, J. J., 1981-1983, p.108)

Así, estamos ante uno de los elementos claves del concepto de representación, tal y como se ha expuesto. El autor del «Libro de Gracián» se apropia del texto de R. Llull, insertando fragmentos en la narrativa que definen la función del príncipe. Ahora bien, el sentido general del texto extraído de la obra de R. Llull se modifica, al menos parcialmente, en el «Libro de Gracián», al explicar la corrupción de los príncipes, y, por tanto, los daños al pueblo, por la influencia de los privados. Esta apropiación y modificación funciona dentro del contexto sociopolítico y cultural de la Castilla de Juan II, en especial en relación con el enfrentamiento de Diego de Anaya (promotor de la obra) con Álvaro de Luna, privado del rey. El autor, posiblemente, lee a R. Llull teniendo como referencia el contexto en el que vive, y así, complementa el texto de R. Llull en el marco sus propias experiencias, en las que el mal gobierno del reino se explica por la acción del privado. El «Libro de Gracián», en cuanto representación, funciona en relación a los conflictos presentes en el reinado de Juan II, incluso a la hora de entender el uso de los textos lulianos.

Profundizando en el carácter polémico del texto, el «Libro de Gracián» destaca explícitamente la idea de enfrentamiento, al calificar a privados y consejeros como "enemigos" del príncipe. ${ }^{15}$ Se trataría de una suerte de estrategia discursiva, de representar la realidad social de manera que se piense al privado como a un enemigo del príncipe, y por lo tanto del orden social. En este sentido se destacan que la acción de los privados es perjudicial para el príncipe. Por una parte, son perjudiciales para su alma. ${ }^{16}$ Por otra, son perjudiciales para sus posesiones, ya que "(...) cresçen en poseer villas, logares, gentes, tesoros, tanto menguan el poderío t sennorío del prínçipe (...)” (Satorre, J. J., 1981-1983, p.114). Además, los daños al príncipe, con el cual se identifica el orden social, son daños al pueblo.

Así, se está construyendo una representación de un conflicto, por el cual los privados son el motivo y la causa de las diferentes desgracias que le ocurren al príncipe y al pueblo. Asimismo, hay una identificación entre el orden social y el orden moral en el príncipe, a través de la doctrina de las dos intenciones lulianas, que se perturba precisamente con la acción de los privados. Así, el sistema de representaciones en el «Libro de Gracián» construye a los privados como un grupo social que resulta una amenaza moral, política y social, a la que estarían expuestos tanto el príncipe como el pueblo. ${ }^{17}$

Más allá de la representación de príncipes y privados, el sistema de representaciones las desviaciones morales de otros grupos sociales también aparecen condicionadas por la influencia de grupos que, de alguna manera, serían ajenos al orden social, especialmente en el caso de los judíos y los conversos. El pensamiento del autor del relato presupone, como en el caso de los príncipes, un pasado más o menos idealizado, ${ }^{18}$ caracterizado por la virtud, el amor a Dios y la ausencia de vicios como la codicia, tan presentes en el pensamiento que transmite el «Libro de Gracián». En especial, la narración insiste en el rol de los caballeros como garantes de dicho orden social, de una manera similar al caso de los príncipes:

"En este tienpo eran los cavalleros, escuderos, çibdadanos, menestrales $t$ las otras gentes de este regno buenos $t$ sin sotileza $t$ cobdiçia mala, en conparaçión de lo que después fue. Los cavalleros eran llanos t sin vanagloria, no de mala cobdiçia t teníanse por contentos de lo que avían (...). Et estos cavalleros atales presçiávanse de fazer bondades por los cuerpos $t$ amavan fazer 
buenas cosas a serviçio de Dios t en pro del prínçipe t del pueblo común. Et aquesto que amavan, aquesto aconsejaban que fiziese el prínçipe." (Satorre, J. J., 1981-1983, p.157)

El «Libro de Gracián» representa, entonces, a los caballeros como un grupo social que, cuando actúan de acuerdo con su función social, son uno de los fundamentos de la sociedad ideal, actuando al servicio de Dios, del príncipe, y del pueblo común. De la misma forma escuderos, ciudadanos, menestrales y labradores formarían parte de ese pasado idílico, caracterizándose por la buena fe, la justicia, la caridad o el buen vestir, entre otros atributos. ${ }^{19}$ Lo que se busca en este tipo de fragmentos es contraponer esta sociedad ideal con la realidad del reinado de Juan II, caracterizado por la codicia, los abusos, el olvido del bien común, o la vanagloria.

Ahora bien, las causas del desorden social vienen dadas principalmente por la corrupción de los caballeros, en este caso por la influencia de los conversos:

\begin{abstract}
"Estos omnes que son fechos conversos, commo son sotiles de entendimiento en las cosas mundanas t sabios de çiençia diabolical t han corronpido las conçiençias, de antes eran temerosos de obrar los males que fazer, $t$ después fueron más osados t estendiéronse entre los xristianos $t$ enxiriéronse con los cavalleros $t$ enduziéronlos a cobdiçia. $t$, monstrándoles sotilezas malas cómmo podrían percançar $t$ allegar dineros, así del prínçipe commo de los pueblos (...). Tanto son çiegos ya algunos cavalleros por esta gente perversa en cobdiçia, que olvidadas son ya por ellos todas las buenas costunbres que eran otros tienpos en los cavalleros (...). t, así commo fizieron a los cavalleros, así induzieron todos los otros estados, de grado en grado, de manera que tantas son las malas costunbres de sotilezas en cobdiçia estendidas en todo el pueblo, que ya es quasi convertido en muchos pecados" (Satorre, J. J., 1981-1983, p.158)
\end{abstract}

La dinámica de esta representación resulta ser similar a la de los privados y príncipes. Frente a un orden social que se proyecta en un pasado idealizado, en el que los caballeros aseguraban el orden social, aconsejando correctamente al príncipe y actuando por el bien del pueblo, es la introducción de un nuevo grupo social (los conversos) lo que corrompe el orden social. En este sentido, el texto está situado en un contexto de crecientes conversiones de judíos al cristianismo, que va de la mano de un proceso de construcción de una idea del converso que a menudo tiene un difícil encaje dentro del orden social. ${ }^{20}$ Este es el caso del «Libro de Gracián», en el que los conversos son un grupo disruptivo dentro de la sociedad, causante de buena parte de los problemas que el autor detecta en el mundo en el que vive.

Las diferentes formas de representar la realidad social del «Libro de Gracián» tienen una serie de dinámicas que pasan por la construcción de un pasado idealizado, en el que el orden social estaba asegurado por la acción de caballeros y príncipes. Este orden es perturbado por la acción de privados y príncipes. En este sentido, frente a otros grupos sociales cuya función aparece más o menos definida (príncipes, caballeros, oficiales, ciudadanos, etc.), los privados y los conversos son los causantes de injurias, abusos, pecados, y decadencia moral, en términos generales. Se trata de una estrategia discursiva, esto es, de la puesta en juego de una serie de recursos a la hora de interpretar, clasificar, argumentar sobre un orden social determinado. Estos recursos incluyen, por supuesto, la apropiación de los textos de Ramón Llull, pero también la reflexión sobre las diferentes funciones de diversos grupos y su relación con el orden social. Finalmente, estas representaciones se realizan en favor de unos intereses, difíciles de delimitar, pero que parecen coincidir, en rasgos generales, con los intereses de Diego de Anaya.

\title{
Conclusiones
}

Partiendo del concepto de representación social es posible analizar ciertos rasgos que configuran el «Libro de Gracián» como un discurso en el que se construye una realidad social determinada. La noción de representación puede entenderse de manera compleja, como el producto del pensamiento, interpretación $\mathrm{y}$ aspiraciones de unos agentes determinados, y que incorpora las formas de clasificación social de dichos agentes, y juicio moral de dichos agentes. El «Libro de Gracián», como relato de viajes con fuerte carga 
sociopolítica, responde a esta definición. No se trata de un reflejo fidedigno de la realidad, sino que se propone una interpretación determinada de dicha realidad, con un fuerte contenido crítico contra privados y conversos, al menos. En este sentido, es posible extraer varias conclusiones:

a) Aunque resulte difícil delimitar que intereses y aspiraciones refleja el «Libro de Gracián», sí sabemos que el texto surge del entorno de Diego de Anaya, y podemos relacionar ciertos elementos de la obra con los círculos intelectuales que conforman el «Cancionero de Baena», así como posiblemente con la Orden de los Jerónimos.

b) El texto se sitúa en un contexto caracterizado por el conflicto político (el reinado de Juan II), e incorpora en él las divisiones y luchas de ese contexto. Así, las fuertes críticas a los privados pueden entenderse como un posicionamiento político, en este caso, reflejando las posiciones enfrentadas de Diego de Anaya con Álvaro de Luna.

c) Las representaciones que presenta el «Libro de Gracián» se elaboran, al menos parcialmente, a partir de la apropiación de textos de Ramón Llull. Los fragmentos lulianos componen parte de la reflexión sociopolítica de la obra, si bien los significados se modifican, aunque sea levemente.

d) Finalmente, en el «Libro de Gracián» se emplea una estrategia de representación determinada. Se contrasta un presente caracterizado por la decadencia y la corrupción moral y política, con una sociedad ideal, proyectada en el pasado. Esta sociedad ideal sirve como un modelo de orden social, que sería corrompido por la aparición de grupos sociales como los conversos y los privados, especialmente debido a su influencia en príncipes y caballeros, cuya función es, precisamente, preservar el orden social.

En definitiva, estamos ante un texto que es posible estudiar de forma práctica y teórica, a través de los diferentes rasgos que hemos destacado del concepto de representación (construcción intelectual, apropiación, clasificación social, etc.), que llevan a presentar el «Libro de Gracián» como un texto que construye una visión determinada de la sociedad en la que se produce.

\section{REFERENCIAS}

Barthes, R. (1994). El susurro del lenguaje. Más allá de la palabra y la escritura. Barcelona: Paidós

Beceiro Pita, I. (2002). Argumentos ideológicos de la oposición nobiliaria bajo los Trastámara. Cahiers d'Études Hispaniques Médiévales, 25, 211-236.

Burke, P. (2006). Formas de historia cultural. Madrid: Alianza Editorial

Chartier, R. (1992). El mundo como representación. Estudios sobre historia cultural. Barcelona: Gedisa

Chartier, R. (2005). El presente del pasado. Escritura de la historia, historia de lo escrito. Universidad Iberoamericana: México D.F.

Chartier, R. (2007). La historia o la lectura del tiempo. Barcelona: Gedisa

Díaz Marcilla, F. J. (2015a). La influencia de Ramón Llull en el entorno del Cancionero de Juan Alfonso Baena. Antonianum, 3 (julio-septiembre), 623-654.

Díaz Marcilla, F. J. (2015b). El hilo luliano de la madeja cultural castellana medieval. Nuevos aportes al lulismo medieval laico y religioso. En J. Higuera Rubio (ed.), Knowledge, contemplation and lullism. Contributions to the lullian session at the SIEPM Congress - Freising, August 20-25, 2012 (pp. 165-190). Turnhout: Brepols.

van Dijk, T. (1998). Ideology: a multidisciplinary approach. Londres: SAGE

Fraker, C. F. (1966). Gonzalo Martínez de Medina, the Jerónimos, and the devotio moderna. Hispanic Review, 34(3), 197-217.

Foucault, M. (1977). What is an author? En M. Foucault y D. F. Bouchard (ed.). Language, counter-memory and practice. Selected essays and interviews (pp. 113-138). Ithaca: Cornell University Press 
Foucault, M. y Serverat, V. (1997). La pourpre et la glèbe. Rhétorique des états de la société dans l'Espagne médiévale. Grenoble: Ellug

Gómez Redondo, F. (2002). Historia de la prosa medieval castellana. Vol. III: los orígenes del humanismo. El marco cultural de Enrique III y Juan II. Madrid: Cátedra

Godelier, M. (1989). Lo ideal y lo material. Madrid: Taurus Humanidades

Guadalajara, J. (1990). Álvaro de Luna y el Anticristo. Imágenes apocalípticas en don Íñigo López de Mendoza. Revista de Literatura Medieval, 2,183-206. Recuperado de: https://dialnet.unirioja.es/servlet/articulo?codigo=150786

Lacapra, D. (1980). Rethinking intellectual history and reading texts. History and theory, 19(3),245-276

Ladero Quesada, M. A. (2016). Los efectos del mal gobierno en la Andalucía de Juan II según la Novela moral de Gracián. Boletín de la Real Academia de la Historia, 213(1),109-149.

Llull, R., Pere Gimferrer (trad.) (1981). Obra escogida. Madrid: Alfaguara

Monsalvo Antón, J. M. (2014). Diego de Anaya (1357-1437) y su tiempo. Aristócrata, obispo, diplomático y humanista. En M. A. Pena González y L. E. Rodríguez-San Pedro Bezares (coords.). La universidad de Salamanca y el pontificado en la Edad Media (pp. 217-254). Salamanca: Publicaciones Universidad Pontificia

Nieto Soria, J. M. (2002-2003). Fragmentos de ideología política urbana en la Castilla bajomedieval. Anales de la Universidad de Alicante, 13, 203-229. Recuperado de: https://doi.org/10.14198/medieval.2000-2002.13.06

Nieto Soria, J. M. (1998). El poderío real absoluto de Olmedo (1445) a Ocaña (1469). En la España Medieval, 21, 159-228. Recuperado de: https://revistas.ucm.es/index.php/ELEM/article/view/ELEM9898110159A/22969

Nieto Soria, J. M. (2017). Álvaro de Luna tirano. Opinión pública y conflicto político en la Castilla del siglo XV. Imago Temporis. Medium Aevum, 11, 488-507. Recuperado de: https://repositori.udl.cat/bitstream/handle/10459.1 /60566/imatem_a2017n11.pdf?sequence=18isAllowed $=y$

Nirenberg, D. (2002). Mass conversion and genealogical mentalities: Jews and Christians in fifteenth century Spain. Past \& Present, 174, 3-41

Nogales Rincón, D. (2006). Los espejos de príncipes en Castilla (siglos XIII-XV): un modelo literario de la realeza bajomedieval. Medievalismo. Boletín de la Sociedad Española de Estudios Medievales, 16, 9-39. Recuperado de: h ttps://revistas.um.es/medievalismo/article/view/50931/49061

Pons, A. y Serna, J. (2005). La historia cultural. Autores, textos, lugares. Madrid: Akal

Satorre, J. J. (1980). La novela moral de Gracián (Un texto inédito del siglo XV). Studia Lulliana, 24(2),165-210.

Satorre, J. J. (1981-1983). La novela moral de Gracián (continuación). Studia Lulliana, 25(1), 83-165;

Satorre, J. J. (1986). La novela moral de Gracián (conclusión). Studia Lulliana, 26(2),165-251.

Serverat, V. (1991). Pour une archéologie du roman : les «états de la société» dans l'œuvre de Ramon Llull. Romania, $112(447-448), 419-423$.

Serverat, V. (2005). Une legitmation islamique de la resistance au tyran au temps de Jean II de Castille: Semblanza y tratado de Gracián (chapitre VIII). Cahiers d'études hispaniques médiévales, 28(1), 391-404.

Trías Mercant, S. (1969). La ética luliana en el 'Félix de les meravelles'. Studia Lulliana, 13 (2-3), 113-132.

Vázquez Janeiro, I. (1992). «Gracián», un «Félix» castigliano del secolo XV. Una ricerca sull'innominato autore. Annali. Sezione Romanza, 34(1), 295-337.

Vizuete Mendoza, J. C. (1986). La biblioteca de Guadalupe: un reflejo de la espiritualidad jerónima. En la España medieval, 5,1335-1346

\section{Notas}

1 El texto también es conocido como Novela moral de Gracián y, de hecho, ha sido editado con este título. Ahora bien, debido a que el relato, en el único manuscrito, que se ha conservado, carece de título, hemos decidido seguir la propuesta de Fernando Gómez Redondo (2002), que argumenta a favor de «Libro de Gracián». Otro posible título seria Semblanza y tratado de Gracián, propuesto por Vincent Serverat (2005) 
2 En relación a la "nueva historia intelectual", véase especialmente el texto de Domenick LaCapra (1980) en el que se argumenta a favor de una perspectiva más abierta a la hora de leer textos, que incluya diferentes contextos (intención autoral, vida del autor, el contexto social y cultural, etc.) pero que no reduzca los significados de un discurso a estas instancias. D. LaCapra argumenta que, de alguna manera, un texto está siempre atravesado por distintas tensiones, ya sea entre elementos "sintomáticos" y "contestatarios", entre la intención del autor y los significados que exceden la propia conciencia del autor, entre diferentes formas de leer el texto y apropiarse de él, etc. En lo tocante a la nueva historia cultural, puede consultarse A. Pons y J. Senra (2005) así como Peter Burke (2006).

3 Sobre la relación entre Diego de Anaya y el manuscrito en el que se encuentra el «Libro de Gracián» (MS 1866, Biblioteca Universitaria de Salamanca), véase J. J. Satorre (1980, pp.189-191)

4 Sobre la noción de autor en general, las reflexiones de pensadores como M. Foucault (1977) o R. Barthes (1994, pp.65-71) apuntan a la posibilidad de pensar a un autor integrado en su contexto, de manera que no sea este el único anclaje a la hora de interpretar los significados de un texto.

5 La configuración de una imagen negativa del Condestable es una constante en los discursos políticos de la época. La figura de don Álvaro incluso llega a adquirir connotaciones apocalípticas, aunque sea de manera implícita, según se argumenta en J. Guadalajara (1990)

6 Si bien el discurso juega un rol en la construcción de la realidad social, esto es, en la producción de acciones, prácticas, hábitos y relaciones, esto no quiere decir que sea el único elemento para considerar a la hora de entender dicha realidad. Según R. Chartier, "la construcción de los intereses por los lenguajes disponibles en un tiempo dado siempre está limitada por los recursos desiguales (materiales, lingüísticos o conceptuales) de los que disponen los individuos” (Chartier, R., 2005, pp.32-34)

7 I. Vázquez Janeiro (1992), destaca las similitudes entre ciertos elementos del «Libro de Gracián» y poetas cuyas obras se recogen en el «Cancionero de Baena», tales como Pedro López de Ayala, Micer Francisco Imperial, Ruy Páez de Ribera y Gonzalo Martínez de Medina. Con este último, guarda ciertas semejanzas en su crítica sociopolítica. Ambos critican el exceso de jueces y abogados en las ciudades cristianas, poniendo como ejemplo a seguir las ciudades musulmanas, en las que hay un solo juez. Según el «Libro de Gracián» “(...) yo fue en una çibdat de los serrazines (...), e avía un solo juez en ella e un escrivano, e todos los días estaba ocçioso, que non vinían a pleito ante él” (Satorre, J. J., 1986, p.178)

8 Véase a este respecto F. Díaz Marcilla (2015a). Quizás la del «Libro de Gracián» con Diego de Anaya, y con el entorno del «Cancionero de Baena». Se ha hablado, en relación a esto, de dos focos en el lulismo castellano del siglo XV. Por una parte, un foco andaluz, en el que estaría presente las menciones a Llull en el «Cancionero de Baena»; y un foco castellano, del que formaría parte el «Libro de Gracián». Sin embargo, existiría una conexión entre ambos focos, precisamente la figura de Diego de Anaya. Véase en este sentido F. Díaz Marcilla (2015b)

9 La relación de los jerónimos, de nuevo, tampoco tiene por qué estar desconectada de las otras dos. En primer lugar, como indica el propio editor, Diego de Anaya tenía relación con esta orden, ya que, cuando es expulsado de la sede sevillana por las intrigas de Álvaro de Luna, se retira a un monasterio jerónimo, San Bartolomé de Lupiana (Monsalvo Antón, J. M., 2014, p.253). En segundo lugar, los jerónimos forman una parte importante de la recepción de R. Llull en Castilla. Para ello véase J. C. Vizuete Mendoza (1986, pp.1335-1346). Finalmente, la espiritualidad jerónima también está presente en la obra de Gonzalo Martínez de Medina, uno de los autores del «Cancionero de Baena» con ideas semejantes a la que están presentes en el «Libro de Gracián». Véase a este respecto, C. F. Fraker (1966)

10 Veamos, como ejemplo, el siguiente fragmento, incluido en el «Libro de Gracián»: “Acaesçió un día que Graçián vido que entre el príncipe t un su escudero era questión, ca dizía el prínçipe que prínçipe puede mas ligeramente ser perdonado que un su escudero t que non avía tan grand culpa, si fiziese pecado, commo avía el súbdito. El escudero le dixo que, segund esto que el prínçipe dizía, se siguiría que el vasallo oviese mayor oportunidad de fazer bien $\mathrm{t}$ de ganar más meresçimiento que el prínçipe; $\mathrm{t}$ seguir se ía que, si en Dios fuese pecado o fallesçimiento, que non fuese mayor que en omne" (Satorre, J. J., 1986, p.195). Este fragmento está extraído y adaptado del «Llibre de meravelles» de R. Llull (1981, pp.245-246). Ahora bien, en la obra de R. Llull se encuentra en una parte dedicada a los vicios y virtudes, en concreto, en un capítulo dedicado a la esperanza y a la desesperanza, siendo un exemplum entre varios con los que se busca explicar dicha virtud y vicio. En el «Libro de Gracián», en cambio, está situado en el capítulo XI, en el cuál, Gracián presencia la educación de un joven príncipe, al cual se presenta de manera fundamentalmente negativa. En este sentido, se podría decir que el autor del relato castellano usa el texto luliano para enfatizar la falta de humildad del príncipe, no explicar la esperanza. Se trata de una forma de apropiarse de la obra luliana, de una manera de leer el texto, de acuerdo con los intereses del autor, que busca fundamentalmente criticar la corrupción moral de la sociedad en la que vive.

11 Así, en el propio prólogo se afirma que el texto recoge las prácticas "que por algunos prínçipes t prelados et por otros omnes de otros estados son obradas contra la voluntad del dicho árbol t su fructo t otros que son plazibles a Dios Nuestro Sennor" (Satorre, J. J., 1981-1983, p.89). En este sentido, la voluntad del autor del texto de que a través del texto se recoja una clasificación de lo social y lo moral está clara. Se trataría, por otra parte, de un tema muy extendido en la literatura de la Castilla bajomedieval. Diferentes tipos de textos (poesía, teatro, tratados políticos, colecciones de exempla, sermones, etc.) de múltiples autores (don Juan Manuel, Pero López de Ayala o Rodrigo Sánchez de Arévalo), por ejemplo, incluyen 
un discurso de clasificación social y moral. Se trataría de una suerte de "formación discursiva", esto es una forma de construir objetos intelectuales que no es asimilable a un tipo de texto, a un espacio determinado o a un grupo social dado, sino que tiene un componente transversal, según ha señalado, siguiendo a M. Foucault y V. Serverat (1997)

12 En este sentido, se ha hablado de una progresiva "absolutización” de la monarquía, por lo menos a nivel discursivo (Nieto Soria, J. M., 1998). También hay un desarrollo, a lo largo de la Baja Edad Media, de un pensamiento aristocrático (Beceiro Pita, I., 2002). Asimismo, también parece ser identificable una ideología urbana en torno a la figura del rey, posicionada de la absolutización antes mencionada (Nieto Soria, J. M., 2000-2002).

13 "Prinçipe, fijo, es con entençión que, con temor, tenga justiçia en su prinçipado: ca, sí commo el Santo Padre Apostólico es en el mundo por entençión que con caridad govierne $t$ mantenga sus sometidos, así, fijo, prínçipe es por entençión que sea temido omnes henemigos de justiçia. Amable fijo, prínçipe deve aver la primera entençión a ganar mérito en su oficio por obra de fe $t$ de sperança t de las otras virtudes, t la segunda entençión deve aver a su oficio; más el demonio, que es contrario a la ordenaçión de las dos entençiones, tienta a los prínçipes, por tal que entençión salga del ordenamiento por que es creada en omne" (Satorre, J. J., 1981-1983, p.104).

14 "Fijo, al comienço que los prínçipes fueron ordenados t puestos en el pueblo, por quanto muy grand cargo t trabajo les era encomendado, fue por el pueblo ordenado que oviesen renta, por tal que oviesen su mantenimiento [et] proveimiento nesçesario $\mathrm{t}$ convenible, por tal que biviesen sirviendo a Dios $\mathrm{t}$ faziendo al pueblo que lo amasen $\mathrm{t}$ temiesen, $\mathrm{t}$ buenas costunbres pusiesen t mantoviesen" (Satorre, J. J., 1981-1983, p.107).

15 "Fijo, mucho enpesçe al omne el enemigo sabio t poder[oso], $t$ más el privado $t$ consejero flaso $t$ cobdiçioso $t$ lisonjero. Et mayor henemigo es del prínçipe aquél que es en consejo t causa de la muerte spiritual (...). Et mayor henemigo es del prínçipe aquél que procura t conseja por que el prínçipe sea deserado del ten prínçipado, que poco dura t es poseído con muchos trabajos et peligros corporales t spirituales (...). Enemigos son de él en quanto son en consejo t favor de la muerte spiritual del prínçipe (...) sojugando a los pueblos en servidumbre de omnes injuriosos t despechando el pueblo t gastando rentas (...) $\mathrm{t}$ faziendo algunas cosas que otros prínçipes pasados esquivaron de fazer” (Satorre, J. J., 1981-1983, p.113).

16 "Et los prínçipes que tal logar t poder dan a los tales cavalleros t privados han de padesçer, por la justiçia de Dios, por todos aquellos males $t$ injurias que son fechas por su causa $t$ su consentimiento. thanles de pagar caramente ante Nuestro Sennor Dios. $t$ aun son en culpa t ocasión de que las ánimas de aquellos a quien son dados los tales logares sean en las infernales penas por las muchas injurias que fazen en aquellos pueblos (...) [et] nin fazen mienda nin confesión" (Satorre, J. J., 1981-1983, p.112)

17 Podríamos hablar, siguiendo esta línea, de “ideología”, en el sentido que T. van Dijk da al término. Para van Dijk, una de las estructuras posibles de una ideología en cuanto sistema de creencias es la de la división y construcción discursiva de un "nosotros" y un "ellos". En esta estructura, el "nosotros" estaría valorado positivamente, y el "ellos" de manera negativa. Resulta complicado, en este sentido, acercarnos al "nosotros" que se construye en el «Libro de Gracián», aunque hay quizás una identificación con el ámbito urbano, ya que el padre de Gracián es un "burgués” y la mayor parte de los abusos ocurren en un entorno urbano. No resulta tan difícil identificar al "otro" ideológico. Los privados se configuran como un elemento negativo durante prácticamente todo el texto, calificándolos de "enemigos", de causantes de injurias y daños, y de todo tipo de prácticas violentas e inmorales. En este sentido, los privados, como los conversos, se constituyen a través del texto como un grupo conflictivo, como un enemigo ideológico. Véase sobre el concepto de ideología aquí recogido, T. van Dijk (1998, pp.65-70).

18 Las representaciones del «Libro de Gracián» recogen, en este sentido, una de las principales funciones del pensamiento, que sería la de crear realidades ideales. La actividad intelectual no se encarga únicamente de interpretar, clasificar o legitimar determinadas realidades sociales, sino que una función fundamental de esta sería la de imaginar realidades alternativas, sociedades idealizadas. El «Libro de Gracián», en este sentido, tiene un claro componente de idealización, comparando continuamente el presente con un pasado incorrupto que resulta ser, a menudo, la inversión de todas las características negativas de la sociedad real que se representa a lo largo de la obra. Esto no quiere decir, por supuesto, que el «Libro de Gracián» presente un discurso rupturista con la sociedad en la que vive, sino que emplea una serie de estrategias discursivas (como la creación de sociedades ideales) para hacer una crítica de carácter moral de la sociedad en la que vive, dando por supuestas sus rasgos sociopolíticos fundamentales (la Iglesia, la monarquía, a división de la sociedad en distintos órdenes o "estados", etc.). Sobre la idea de que el pensamiento genera realidades ideales, véase M. Godelier (1989)

19 "Los escuderos eran senblantes a los cavalleros, ca de ellos tomavan exenplo. Los ofiçiales de la corte del prínçipe $t$ de las villas $\mathrm{t}$ logares $\mathrm{t}$ çibdades del prinçipado presçiávanse de dar juizios $\mathrm{t}$ fazer justiçia a los pobres $\mathrm{t}$ a las otras personas miserables. Los çibdadanos bevían en sus faziendas justamente $\mathrm{t}$ a buena fe $\mathrm{t}$ sin vanagloria (...). Eran limosneros $\mathrm{t}$ caridosos $t$, por semejante manera, los menestrales $t$ labradores todos estavan en posesión de bien bevir $t$ eran llanos $t$ humildes t ordenados en sus vestires, comeres t en las otras despensas, segund la grand desordenación que oy es" (Satorre, J. J., 1981-1983, pp.157-158). 
Roque Sampedro López. El Libro de Gracián como representación social (Castilla, siglo XV)

20 Véase, por ejemplo, D. Nirenberg (2002), que argumenta que las conversiones en masa desde finales del siglo XIV, conversiones que a menudo tenían un componente coercitivo, generan una desestabilización de las categorías religiosas tradicionales, dando lugar a nuevas formas de entender las distinciones colectivas entre judíos y cristianos.

\section{BY-NC-SA}

